\title{
Educação na Faixa: um Jogo 2D para o Ensino da Educação Para o Trânsito
}

\author{
Jarles Tarsso Gomes Santos ${ }^{1}$, Cintia Reis de Oliveira ${ }^{1}$, Crisiany Alves de Sousa ${ }^{\mathbf{1}}$, \\ Charles Andryê Galvão Madeira ${ }^{1}$, André Maurício Cunha Campos ${ }^{1}$
}

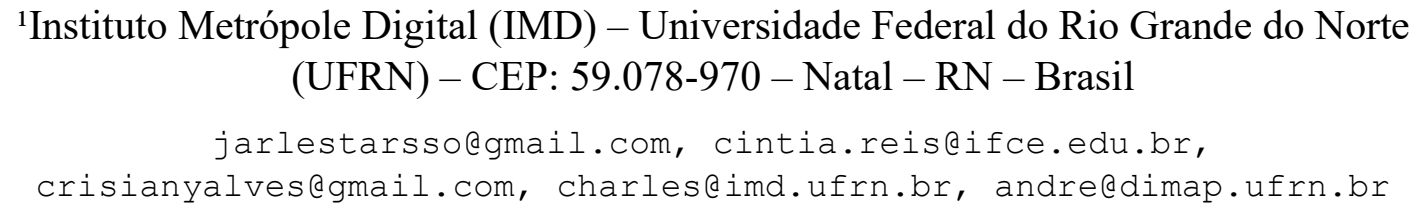

\begin{abstract}
Traffic education is a cross-cutting theme that aims to provide the student with the necessary knowledge about traffic. Therefore, the school plays an essential role, preparing young people to act beyond the classroom. However, the teacher still has difficulty in addressing this topic, which is often not taught to the student correctly. To overcome this problem, the present study proposes to show the first version of Educação na Faixa, a 2D game developed on the Construct 3 platform, as a guide to approach concepts related to traffic, so that students can simulate situations that they will experience in the future. The game has been tested and the feedback will serve for future improvements in the mechanics contained in the game.
\end{abstract}

Resumo. A educação para o trânsito é um tema transversal que visa proporcionar ao estudante o conhecimento necessário acerca do trânsito. Nesse sentido, a escola passa a exercer um papel fundamental, preparando o jovem para atuar fora da sala de aula. Entretanto, o professor ainda encontra dificuldades para abordar esse tema, que muitas vezes não é mostrado ao estudante da maneira adequada. Buscando contornar esse problema, o presente estudo apresenta a primeira versão do Educação na Faixa, um jogo 2D desenvolvido na plataforma Construct 3, como forma de abordar conceitos referentes ao trânsito, em que o estudante pode simular situações que vivenciará no futuro. O jogo foi testado e o feedback servirá para futuras melhorias nas mecânicas apresentadas.

\section{Introdução}

A educação para o trânsito tem se tornado uma temática bastante discutida em diversos estudos. Nas escolas, é comum observarmos cada vez mais ações que visam trazer ao estudante conhecimentos pertinentes para a condução de um trânsito seguro, seja em grandes ou pequenas cidades. A Lei $\mathrm{n}^{\circ}$ 9.503/97 em seu Art. 76, aborda que a educação para o trânsito deve ser promovida em escolas, levando em consideração todos os níveis de ensino, mediante o planejamento de ações entre órgãos competentes.

Segundo o Mapa do Brasil da Educação para o Trânsito, disponível no site do Denatran, dos 27 estados da Federação, apenas 17 mostram ações desenvolvidas pelo Sistema Nacional de Trânsito. Destaque para o Rio Grande do Norte, local onde este estudo foi desenvolvido, que não está incluso no grupo dos que realizam ações de 
VIII Congresso Brasileiro de Informática na Educação (CBIE 2019)

Anais do XXV Workshop de Informática na Escola (WIE 2019)

educação para o trânsito, o que motiva este estudo para o desenvolvimento de intervenções nesse aspecto.

De acordo com as Diretrizes Nacionais da Educação para o Trânsito, essa temática deve ser tratada de forma transversal e interdisciplinar dentro de sala aula. $\mathrm{O}$ documento apresenta propostas pedagógicas para que o professor desenvolva atividades em diversas disciplinas, afirmando que a educação para o trânsito não deve ser abordada apenas no seu contexto técnico, mediante a aprendizagem das leis de trânsito, mas sim em um contexto no qual o estudante possa desenvolver valores relacionados à ética e à cidadania.

A Base Nacional Comum Curricular (BNCC) trata a educação para o trânsito como um tema que afeta a vida humana em escala local, regional e global [Brasil 2017]. $\mathrm{O}$ documento aborda algumas habilidades pertinentes às áreas de Língua Portuguesa (EF69LP24 e EF67LP15) e Matemática (EF05MA24 e EF06MA32) no ensino fundamental, que servem como norteadoras para a condução de atividades que abordam a educação para o trânsito ou utilizam indicadores que afetam a vida no trânsito como intermédio para aprender conceitos estatísticos e probabilísticos, bem como para a construção de textos interpretativos sobre fatos que acontecem no trânsito.

Existem diversas abordagens que podem ser utilizadas para a inserção da educação para o trânsito em sala de aula, dentre as quais destacam-se os jogos digitais. De acordo com Silva et al. (2014) a ludicidade proporcionada pelos jogos permite gerar motivação no estudante, devido a possibilidade que o jogador ganha para interagir em um ambiente interativo, em que ele é capaz de ter controle sobre as situações vivenciadas e alcançar níveis maiores, de acordo com o seu progresso.

Prensky (2001) afirma que os jogos não são o único caminho para melhorar o contexto educacional. Entretanto, aponta os jogos digitais como um dos requisitos para engajar as novas gerações nos conteúdos propostos em sala de aula. A esse método de aprendizagem, o autor denomina Digital Game-Based Learning ou Aprendizagem Baseada em Jogos Digitais.

Aos jogos digitais, Prensky (2001) atribui a possibilidade de lidar com uma infinidade de conteúdos e cenários. Além disso, proporcionam maior diversão aos jogadores e torna possível maior interação entre o jogador e o conteúdo, facilitando principalmente para estudantes com dificuldades para concentração e/ou aprendizado.

Muitos estudos apresentam o desenvolvimento de jogos digitais para o ensino da educação para o trânsito. Porém, um grande problema encontrado na literatura é a falta de adaptação no que diz respeito aos documentos oficiais que norteiam a educação no Brasil. Além disso, a maior parte dos jogos desenvolvidos não são disponibilizados em repositórios acessíveis, impedindo que o professor possa utilizá-los em sala.

Partindo desse pressuposto, este trabalho busca apresentar a proposta inicial do jogo Educação na Faixa ${ }^{1}$, desenvolvido na plataforma Construct 3, como ferramenta de auxílio ao professor para o ensino da educação para o trânsito, nos níveis do ensino fundamental I e II. O jogo é norteado principalmente pela habilidade EF69LP24 presente no documento da BNCC, que busca discutir casos reais ou simulações que envolvam o desrespeito a artigos do Código Nacional de Trânsito, buscando familiarizar o estudante com situações que serão vivenciadas por eles [Brasil 2017].

\footnotetext{
${ }^{1}$ Disponível em: https://educacaonafaixa.netlify.com.
} 
VIII Congresso Brasileiro de Informática na Educação (CBIE 2019)

Anais do XXV Workshop de Informática na Escola (WIE 2019)

O jogo foi validado com estudantes de um Curso de Informática, que contempla atividades de desenvolvimento de jogos, buscando avaliar aspectos de usabilidade e aspectos pedagógicos oferecidos pelo jogo, para posterior análise dos resultados e melhoria da proposta.

\section{Trabalhos Relacionados}

Alguns estudos abordam o desenvolvimento de jogos visando educar para o trânsito, usando diversas estratégias e plataformas para a conclusão do jogo. Santos, Coan e Romão (2016) apresentam um jogo 2D desenvolvido na plataforma Construct 2, em que o jogador deve tomar decisões acerca de situações de trânsito. $\mathrm{O}$ jogo permite que o jogador realize interações, que são apresentadas em forma de perguntas, que retornam um feedback ao aluno, dependendo da sua resposta. Os autores afirmam que um jogo dessa natureza pode contribuir para que o estudante ganhe estímulo para a aprendizagem acerca do trânsito.

Macedo et al. (2013) apresentam um jogo 3D intitulado IntEducaTrânsito, em que é possível simular o volante de um carro de uma autoescola, apresentando-se como uma espécie de simulador para o trânsito. De acordo com os autores, o jogo permite que o usuário controle os personagens por meio de dispositivos como joystick, volantes, tablet e smartphone, além do teclado convencional.

O jogo 3D Induca [Santana, Tronto e Sousa 2018] simula uma cidade na qual o jogador deve seguir obedecendo as regras de trânsito. Ao contrário da maioria dos jogos, que colocam o jogador na situação de motorista, o jogo traz como personagem um pedestre. O Induca é divido em fases e possui diversas missões que devem ser seguidas pelo jogador, como andar pela rua respeitando a sinalização de trânsito.

Silva et al. (2014) desenvolveram o Educa Trânsito, que aborda as consequências geradas pela imprudência e a falta de conhecimento no trânsito. $O$ jogo não permite que o estudante guie o personagem. Entretanto, são apresentadas animações 3D, que ocorrem de acordo com as respostas fornecidas pelo jogador aos questionamentos que são exibidos na tela.

O CidTrans [Azzolini, Assis e Pontarolo 2014] é um jogo 3D que visa apoiar a formação de condutores e alunos do ensino fundamental. Trata-se de um jogo que apresenta diversos desafios ao jogador, desde pedestres atravessando fora da faixa, motoristas que não respeitam semáforo, dentre outros. Os autores defendem que jogos digitais podem servir de auxílio para conscientizar a respeito da educação para o trânsito, em que o condutor pode conhecer normas seguras para atuar no contexto real.

Todos os jogos analisados serviram de aporte para o desenvolvimento do jogo Educação na Faixa, que traz como diferencial o embasamento em habilidades contempladas pela BNCC, bem como o conteúdo apresentado pelas Diretrizes Nacionais da Educação para o Trânsito no Ensino Fundamental. Além disso, a bibliografia apresentada não permite que o professor acesse o jogo para que possa validá-lo com sua turma.

\section{Metodologia}

A implementação do jogo proposto aconteceu na plataforma de desenvolvimento Construct 3, que permite realizar o desenvolvimento de jogos $2 \mathrm{D}$ de forma fácil e rápida, 
VIII Congresso Brasileiro de Informática na Educação (CBIE 2019)

Anais do XXV Workshop de Informática na Escola (WIE 2019)

mesmo que o usuário tenha pouco conhecimento acerca de programação. De acordo com a Scirra, empresa responsável pela ferramenta Construct, a plataforma de desenvolvimento permite a implementação de jogos específicos, sem a necessidade de usar codificação.

Para o desenvolvimento do jogo, foram analisadas as Diretrizes Nacionais da Educação para o Trânsito e a BNCC, buscando identificar como a educação para o trânsito deve ser abordada em sala de aula. Diante disso, foi pensando em um jogo que permita ao estudante exercer a função de motorista de um veículo, de modo que ele possa percorrer estradas até o seu objetivo final.

Após a definição da temática do jogo, foi realizado um levantamento bibliográfico, buscando localizar jogos com temática semelhante, para que o jogo não se torne mera repetição. A análise encontrou os jogos já mencionados na seção anterior. Outros jogos foram analisados, porém não permitiam que o jogador controle um personagem, se limitando a responder questionamentos que são exibidos na tela.

Posterior ao levantamento bibliográfico, foram identificados os aspectos pedagógicos a serem inseridos no jogo (Tabela 1). Optou-se por trabalhar conteúdos presentes na orientação das Diretrizes Nacionais da Educação para o Trânsito no Ensino Fundamental, que divide os conteúdos em blocos, para que sejam lecionados pelo professor durante toda a fase do ensino fundamental.

Tabela 1. Aspectos pedagógicos presentes no jogo.

\begin{tabular}{|c|l|l|}
\hline Bloco & \multicolumn{1}{|c|}{ Conteúdo } & \multicolumn{1}{|c|}{ Dinâmica do jogo } \\
\hline A cidade & $\begin{array}{c}\text { Importância da } \\
\text { acessibilidade; } \\
\text { - Vagas de veículos para } \\
\text { deficientes físicos. }\end{array}$ & $\begin{array}{l}\text { O jogador encontra-se em uma situação } \\
\text { em que deve estacionar o veículo } \\
\text { orretamente, respeitando a vaga } \\
\text { destinada a deficientes físicos. }\end{array}$ \\
\hline $\begin{array}{c}\text { As linguagens } \\
\text { do trânsito }\end{array}$ & $\begin{array}{l}\text { Os sinais de trânsito e sua } \\
\text { importância para uma } \\
\text { locomoção segura. }\end{array}$ & $\begin{array}{l}\text { Apresentação de placas e sinais de } \\
\text { trânsito, mostrando ao estudante a } \\
\text { proposta de cada sinal e induzindo-o a } \\
\text { respeitá-los, quando necessário. }\end{array}$ \\
\hline $\begin{array}{c}\text { Segurança no } \\
\text { trânsito }\end{array}$ & $\begin{array}{l}\text { Importância do uso do } \\
\text { cinto e demais } \\
\text { equipamentos de } \\
\text { segurança. }\end{array}$ & $\begin{array}{l}\text { Obrigatoriedade do uso do cinto de } \\
\text { segurança no início de cada fase. }\end{array}$ \\
\hline $\begin{array}{c}\text { Convivência } \\
\text { social no } \\
\text { trânsito }\end{array}$ & $\begin{array}{l}\text { - Dar a vez, ceder o lugar; } \\
\text { - Responsabilidade do } \\
\text { condutor sobre o pedestre. }\end{array}$ & $\begin{array}{l}\text { Respeito a elementos presentes no } \\
\text { trânsito, como semáforo e faixa de } \\
\text { pedestres. }\end{array}$ \\
\hline
\end{tabular}

Buscando validar o jogo, foi realizada uma atividade com estudantes de um Curso de Informática, em que a proposta do jogo foi apresentada e os estudantes puderam testálo. Posteriormente, foi aplicado um formulário, elaborado na ferramenta Google Forms, de acordo com as ideias de Silva et al. (2014). O formulário abordou questões referentes 
VIII Congresso Brasileiro de Informática na Educação (CBIE 2019)

Anais do XXV Workshop de Informática na Escola (WIE 2019)

à usabilidade do jogo e sua proposta pedagógica. Os dados coletados servirão como feedback aos desenvolvedores, buscando aplicar melhorias no jogo.

\section{O Jogo Educação Na Faixa}

O jogo Educação na Faixa é composto por um cenário 2D (Figura 1), em que o jogador deve guiar um carro por ruas, até o destino especificado em casa fase. Durante o percurso, o jogador se depara com diversas situações, como semáforos, placas de trânsito e faixa de pedestres, que deverão ser respeitadas para que o jogador consiga prosseguir.

No intuito de tornar o jogo adequado para o nível ao qual se destina, o Educação na Faixa apresenta um cenário composto por elementos como moedas e tempo, além de animações e efeitos sonoros que são característicos dos jogos presentes no mercado de games atual.

O jogo conta com alguns fatores essenciais apresentados por Prensky (2001), como é possível observar abaixo:

1. Regras - mostra o que o jogador pode ou não fazer dentro do jogo e ajuda a diferenciar um momento de aprendizagem a uma simples brincadeira.

2. Metas ou objetivos - contribuem para motivar o estudante a alcançar o propósito do jogo.

3. Resultados e feedback - o feedback é essencial para garantir a aprendizagem do estudante, pois é por meio dele que o jogador pode aprender.

4. Conflito/competição/desafio/oposição - dizem respeito aos problemas que os jogadores deverão resolver dentro do jogo. É fator primordial para definir se o jogador continuará ou não jogando.

5. Representação ou enredo - apresenta o significado do jogo, denotando algo real ou mesmo abstrato.

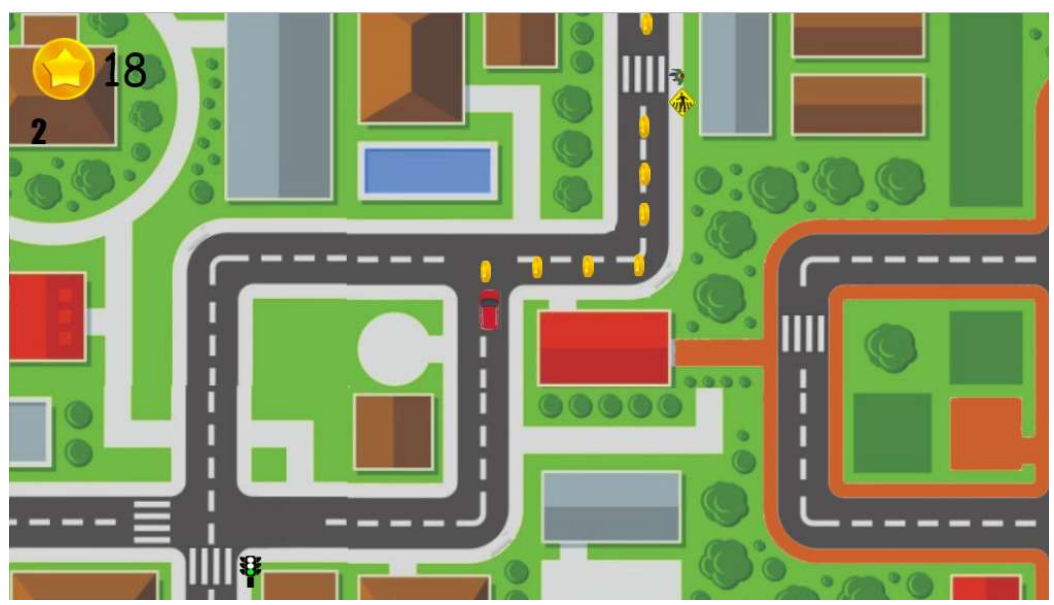

Figura 1. Cenário do jogo.

Para auxiliar o jogador, um personagem caracterizado como um guarda de trânsito o ensina as regras de trânsito (Figura 2). Diante disso, o jogador deve respeitá-las, para que consiga avançar até o seu destino. Caso o jogador desrespeite alguma norma de trânsito, é levado ao reinício do jogo, em que deve observar novas orientações do guarda de trânsito, na tentativa de reforço ao aprendizado. 
VIII Congresso Brasileiro de Informática na Educação (CBIE 2019)

Anais do XXV Workshop de Informática na Escola (WIE 2019)

As fases do jogo evoluem gradativamente, de forma que a cada uma delas o jogador pode aprender novos conceitos em relação ao trânsito. As orientações iniciais deixam de ser exibidas em certo momento, à medida em que o jogador evolui no jogo, considerando que o aprendizado sobre determinado conteúdo já foi vencido.

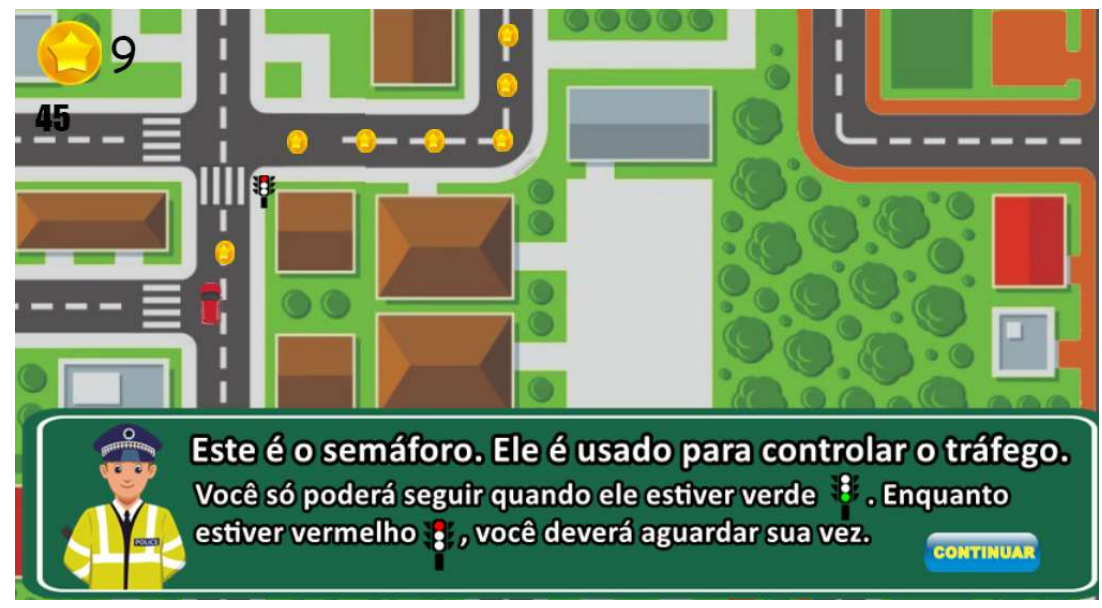

Figura 2. Orientações fornecidas ao jogador.

\section{Validação do Jogo e Discussão}

A validação do jogo aconteceu no Instituto Metrópole Digital, em uma turma de 12 alunos, que fazem parte de um Curso de Informática. A turma é composta por alunos de faixa etária variando entre 15 e mais de 50 anos e possuem grau de escolaridade diversificado, indo dos níveis fundamental ao superior. A escolha da turma aconteceu devido à familiaridade que possuem com o processo de desenvolvimento de jogos e o principal objetivo da aplicação foi a obtenção de um feedback dos participantes a respeito de aspectos técnicos e pedagógicos do jogo, como a definição da melhor faixa etária de aplicação do mesmo e a escolha dos elementos de jogos pertinentes ao fator motivação.

Visando contemplar a aplicação, os alunos tiveram computadores à disposição e o jogo foi disponibilizado através de um endereço eletrônico, de forma que ficasse acessível para a turma. Inicialmente, a proposta do jogo foi explorada, repassando as instruções sobre a temática do jogo e os aspectos pedagógicos desejados.

Ao término da jogatina, os alunos foram sondados por meio de um questionário fechado, buscando coletar dados sobre suas impressões (Tabela 2). As perguntas versaram sobre os aspectos de usabilidade do jogo e os aspectos pedagógicos identificados. As opções de resposta foram compostas por Atende, Atende Parcialmente e Não Atende. 
VIII Congresso Brasileiro de Informática na Educação (CBIE 2019)

Anais do XXV Workshop de Informática na Escola (WIE 2019)

Tabela 2. Dados coletados do questionário de avaliação.

\begin{tabular}{|c|c|c|c|}
\hline \multicolumn{4}{|c|}{ USABILIDADE DO JOGO } \\
\hline Pergunta & Atende & $\begin{array}{c}\text { Atende } \\
\text { Parcialmente }\end{array}$ & Não atende \\
\hline O tema proposto é fácil de entender. & $100 \%$ & $0 \%$ & $0 \%$ \\
\hline É motivador e envolvente. & $33,3 \%$ & $66,7 \%$ & $0 \%$ \\
\hline As mensagens são fáceis de ler e compreender a ideia. & $100 \%$ & $0 \%$ & $0 \%$ \\
\hline $\begin{array}{c}\text { Permite que seja usado sem a necessidade de outra } \\
\text { pessoa passar orientações. }\end{array}$ & $91,7 \%$ & $0 \%$ & $8,3 \%$ \\
\hline Permite repetir fases, sem que torne o jogo cansativo. & $41,7 \%$ & $50 \%$ & $8,3 \%$ \\
\hline $\begin{array}{l}\text { As regras estão de acordo com o mundo imaginário } \\
\text { apresentado. }\end{array}$ & $100 \%$ & $0 \%$ & $0 \%$ \\
\hline \multicolumn{4}{|c|}{ ASPECTOS PEDAGÓGICOS } \\
\hline Pergunta & Atende & $\begin{array}{c}\text { Atende } \\
\text { Parcialmente }\end{array}$ & Não atende \\
\hline $\begin{array}{l}\text { O conteúdo apresentado contribui para a aprendizagem } \\
\text { de um tema importante. }\end{array}$ & $91,7 \%$ & $8,3 \%$ & $0 \%$ \\
\hline $\begin{array}{l}\text { Oferece feedback, ou seja, permite que o estudante } \\
\text { compreenda que errou e aprenda com o erro. }\end{array}$ & $66,7 \%$ & $33,3 \%$ & $0 \%$ \\
\hline $\begin{array}{l}\text { Traz o conteúdo à vivência do estudante, permitindo } \\
\text { que aprenda algo que possa ser útil. }\end{array}$ & $91,7 \%$ & $8,3 \%$ & $0 \%$ \\
\hline
\end{tabular}

Os dados obtidos apontam que o jogo possui uma proposta de fácil entendimento. Porém, grande parte dos alunos $(66,7 \%)$ considera que o fator motivação não é totalmente contemplado pelo jogo. Silva Neto et al. (2013) identificou que o uso de jogos no contexto educacional diverte os estudantes e serve como fator motivacional para a aprendizagem. Portanto, um jogo que não possui essa característica, pode trazer um momento de frustração para o professor em sala, devido ao risco de não atender a aprendizagem proposta.

A respeito da ideia apresentada pelo jogo, todos concordaram que não há dificuldade na compreensão, porém ao menos dois alunos aconselharam reduzir a quantidade de textos, pois para uma criança pode constituir excesso de informação. Além disso, alertaram para o fato de que a grande quantidade de texto pode prejudicar a autonomia do usuário, sendo necessário que o professor atue como mediador.

De fato, a cada novo elemento de trânsito apresentado ao jogador, um pequeno texto surge para que possa orientá-lo a prosseguir no jogo. Como já mencionado, o texto aparece apenas uma vez para cada novo conceito, de forma que o jogador deverá assimilar, para que não precise da orientação nas próximas vezes em que se depare com um conceito já visto. Uma possibilidade para contornar esse possível empecilho pode ser a inserção de orientações sonoras, que apareçam em conjunto com os textos exibidos ao jogador.

Sobre a repetição das fases, ao cometer uma infração, a maior parte $(58,3 \%)$ afirmou que o jogo torna-se cansativo. Um dos entrevistados alegou que a demora para aguardar o semáforo e o tempo para que o pedestre atravesse a faixa, faz com que o jogador perca a paciência enquanto joga. Entretanto, ações desse tipo são constantemente requeridas para atuar em segurança no trânsito. De acordo com Steigleder (2011) as relações no trânsito vêm se tornando cada vez mais tensas, havendo grande impaciência 
VIII Congresso Brasileiro de Informática na Educação (CBIE 2019)

Anais do XXV Workshop de Informática na Escola (WIE 2019)

de motoristas com relação a travessia de pedestres, mesmo que isso vá contra o Código de Trânsito Brasileiro.

Por fim, todos concordaram que o jogo se adequa ao mundo imaginário que se propõe, ou seja, o ambiente pode ser eficiente para simular a atuação do jogador no trânsito, bem como algumas regras e condições que eles irão observar ao vivenciar na prática.

Com relação aos aspectos pedagógicos, grande parte $(91,7 \%)$ concordou que o jogo pode contribuir para a aprendizagem de um tema relevante ao estudante. O mesmo total afirmou que o conteúdo presente no jogo remete à realidade do estudante, de modo que ele pode aprender algo que será útil para sua vida.

Sobre o feedback oferecido ao jogador, um terço dos entrevistados $(33,3 \%)$ afirmou que o jogo não permite que o estudante compreenda que errou e aprenda com o erro, mesmo que seja exibida uma mensagem sobre o erro, a cada infração. Na visão de McGonigal (2012) o feedback constitui elemento essencial em jogos digitais, principalmente quando são utilizados em contextos de aprendizagem. Uma atividade envolvendo jogos, por si só, não é suficiente para garantir a aprendizagem, é preciso acompanhar se o estudante conseguiu assimilar o conteúdo apresentado e fornecer algum feedback para eles [Savi e Dra 2008].

Além de analisar os aspectos de usabilidade e os aspectos pedagógicos, o questionário contava com uma última questão opcional, na qual cada entrevistado poderia sugerir novas opiniões acerca de suas impressões sobre o jogo. Alguns apontaram para os controles do jogo, que poderiam usar, além das setas do teclado, teclas sugeridas por jogos mais convencionais. Outro ponto citado com relação ao controle do jogo, foi a possibilidade de avançar as mensagens sem a necessidade de usar o clique do mouse, sendo feito por meio do teclado do computador.

Sobre as plataformas disponíveis, um dos entrevistados sugeriu a adaptação para dispositivos móveis, tendo em vista a enorme expansão dos tablets e smarpthones. De acordo com dados da Newzoo (2018), até o ano de 2021, a previsão é que o mercado mobile seja responsável por $59 \%$ da receita gerada com jogos eletrônicos.

\section{Considerações Finais}

A proposta aqui apresentada buscou expor o desenvolvimento de um jogo educacional que visa proporcionar ao contexto de sala de aula uma simulação acerca de uma temática relevante aos estudantes, indo além da apresentação de conteúdos teóricos, fazendo com que o estudante possa vivenciar aquilo que ele enfrentará fora da escola.

A técnica de validação do jogo por estudantes com conhecimento pertinente ao desenvolvimento de jogos mostrou-se eficiente para buscar melhorias significativas para o jogo, pois o feedback permitiu que os desenvolvedores observassem lacunas ainda existentes no jogo, tanto nos aspectos de usabilidade, como também pedagógicos.

Diante das opiniões durante a validação, ficou evidente a necessidade de melhorias para que o jogo possa ser validado junto a estudantes dos níveis ao qual se destina, de modo que possa beneficiar efetivamente a aprendizagem acerca da educação para o trânsito. A validação também permitiu perceber elementos importantes que devem compor um jogo educacional, como a escolha correta de imagens e sons, buscando agregar o fator motivação do estudante. 
VIII Congresso Brasileiro de Informática na Educação (CBIE 2019)

Anais do XXV Workshop de Informática na Escola (WIE 2019)

A ferramenta Construct 3 mostrou-se de grande auxílio para o desenvolvimento de jogos a curto prazo, tornando o processo de construção simplificado, devido à ausência de códigos mais complexos. Além disso, permite que o jogo seja exportado para diferentes plataformas, como o sistema Android e $I O S$, mencionados durante a avaliação realizada.

O jogo Educação na Faixa passará por uma nova etapa no seu desenvolvimento, considerando o feedback coletado, para que posteriormente torne-se um produto final. Uma nova validação poderá ocorrer junto aos estudantes que contribuíram na primeira etapa dos testes, para apresentar os resultados do primeiro momento, bem como observar novas lacunas ainda existentes no jogo.

\section{Referências}

Azzolini, V. L., Assis, G. A., Pontarolo, E. (2014). CidTrans: Um Jogo para Educação de Condutores no Trânsito Urbano. In: XXV Simpósio Brasileiro de Informática na Educação (SBIE).

Brasil. (2017). Base Nacional Comum Curricular: educação é a base. Brasília: MEC. $<$ http://basenacionalcomum.mec.gov.br/images/BNCC_EI_EF_110518_versaofinal_ site.pdf $>$. Acesso em 31 de maio de 2019.

Denatran. (2009). Diretrizes Nacionais da Educação para o Trânsito no Ensino Fundamental. Portaria $n^{\circ}$ 147/2009.

Macedo, D. V., Serpa, Y. R., Serpa, Y. R., Abreu, A. P., Rodrigues, M. A. (2013). IntEducaTrânsito: um jogo 3D interativo e educativo sobre as normas de trânsito controlado por dispositivos não tradicionais. In: Simpósio Brasileiro de Jogos e Entretenimento Digital (XII SBGames).

McGonigal, Jane. (2012). A realidade em jogo: por que os games nos tornam melhores e como eles podem mudar o mundo. Rio de Janeiro: Best Seller.

Prensky, M. (2001). Digital Game-Based Learning. New York: McGraw-Hill.

Santana, A. D., Tronto, I. F. B., Sousa, P. M. (2018). Jogo educativo para auxílio na Educação no Trânsito. Revista Brasileira de Educação e Cultura, 17(1).

Santos, G. A., Coan, W. S., Romão, L. M. (2016). Jogo Educacional sobre Educação para o Trânsito. In: Simpósio Brasileiro de Jogos e Entretenimento Digital (XV SBGames).

Savi, R., Dra, V. R. U. (2008). Jogos Digitais Educacionais: benefícios e desafios. Novas Tecnologias na Educação, 6(2).

Silva, J. W. S., Rodrigues, D. S., Dantas, D., Nunes, V. B., Nobre, I. A. M. (2014). Educa Trânsito - Um jogo de apoio à educação no trânsito. Novas Tecnologias na Educação, $12(2)$.

Silva Neto, S. R., Santos, H. R. M., Souza, A. A., Santos, W. O. (2013). Jogos Educacionais como Ferramenta de Auxílio em Sala de Aula. In: XIX Workshop de Informática na Escola (WIE). 
VIII Congresso Brasileiro de Informática na Educação (CBIE 2019)

Anais do XXV Workshop de Informática na Escola (WIE 2019)

Steigleder, C. N. (2011). Trânsito e Pedestres: representações sociais, segregação urbana e conflitos no uso do espaço público. Dissertação de Mestrado - Universidade Federal do Rio Grande do Sul, Porto Alegre. 